\title{
THE METROLOGY OF GROUND CONCRETE SURFACES MORPHOLOGY WITH 3D LASER SCANNER
}

\author{
Lukasz Sadowski $^{1}$, Thomas G. Mathia ${ }^{2}$ \\ 1 Wroclaw University of Technology, Faculty of Civil Engineering \\ ${ }^{2}$ École Centrale de Lyon, Laboratoire de Tribologie et Dynamique des Systèmes \\ Corresponding author: \\ Lukasz Sadowski \\ Wroclaw University of Technology \\ Faculty of Civil Engineering \\ Wybrzeże Wyspiańskiego 27, 50-370 Wroctaw, Poland \\ phone: (+48) 71 320-27-42 \\ e-mail: lukasz.sadowski@pwr.edu.pl
}

Received: 19 March 2015

Accepted: 8 May 2015

\begin{abstract}
This paper is devoted to machining of concrete by grinding and the metrology of its surface morphologies. The surface morphology is still open problem from metrological as well as mathematical morphology points of views. In order to understand better abrasive process the raw morphologic state is compared with the ground concrete surfaces. The most significant results are presented in the form of profiles, 3D isometric views and isotropy analysis. Several 3D surface roughness parameters were calculated.
\end{abstract}

KEYWORDS

concrete, metrology, morphology, 3D laser scanner, grinding, roughness parameters.

\section{Nomenclature}

\begin{tabular}{|c|c|c|}
\hline$S q$ & - & root mean square height $[\mathrm{mm}]$, \\
\hline Ssk & - & skewness $[-]$, \\
\hline$S k u$ & - & kurtosis $[-]$ \\
\hline$S p$ & - & maximum height of summits $[\mathrm{mm}]$, \\
\hline$S v$ & - & maximum depth of valleys $[\mathrm{mm}]$, \\
\hline$S z$ & - & maximum height $[\mathrm{mm}]$, \\
\hline$S a$ & - & arithmetic mean height, $[\mathrm{mm}]$, \\
\hline$S m r$ & - & areal material ratio [\%], \\
\hline$S m c$ & - & inverse areal material ratio $[\mathrm{mm}]$, \\
\hline Sxp & - & extreme peak height $[\mathrm{mm}]$, \\
\hline Sal & - & auto-correlation length $[\mathrm{mm}]$ \\
\hline Str & - & spect ratio $[-]$, \\
\hline Std & - & texture direction $\left[^{\circ}\right]$, \\
\hline$S d q$ & - & root mean square gradient $[-]$, \\
\hline$S d r$ & - & developed interfacial area ratio $[\%]$, \\
\hline$V m$ & - & material volume $\left[\mathrm{mm}^{3} / \mathrm{mm}^{2}\right]$ \\
\hline$V v$ & - & void volume $\left[\mathrm{mm}^{3} / \mathrm{mm}^{2}\right]$ \\
\hline$V m p$ & - & peak material volume $\left[\mathrm{mm}^{3} / \mathrm{r}\right.$ \\
\hline$V m c$ & - & core material volume $\left[\mathrm{mm}^{3} / \mathrm{mn}\right.$ \\
\hline$V v c$ & - & core void volume $\left[\mathrm{mm}^{3} / \mathrm{mm}^{2}\right]$ \\
\hline
\end{tabular}

\section{Introduction}

It has been generally admitted, essentially for economical reasons, that final concrete surfaces are raw and only in specific cases will be machined $[1,2]$.
Recent technological progress in Civil Engineering and worldwide diversified requirements contributes to development of new science surfometry concerning metrology of surfaces. It is not only due to increasing interest of sensor analysis and good looking impression of concrete but also thanks to growing quality of coatings and of its adhesion quantification depending also on roughness.

The surface morphology is still open problem from metrological as well as mathematical morphology points of view [3-8]. Today there are great number of techniques for surfaces metrology of machined or not surfaces but mostly devoted to mechanical industry due to tremendously increasing demand. That proliferation of multi-scale techniques from optical non-contact to tactile devices connected to rash parameters created a great number of industrial difficulties [9]. In recent years has been observed a proliferation of parameters justified or not for description and metrological approach to specify surface texture. Some of these parameters are useful, but most are not even for mechanical industry. The result of this rash is confusion and expense.

For concrete morphology description situation is opposite to previous case. There is total lack of knowledge and specific metrological equipment's. 
The tactile techniques are eliminated for time consuming reasons on the one side and wear problems of the tip on another side [10]. The authors present the today's morphological aspect of concretes in context of control of machining and functional as well as architectural aspects . For specific application reasons in present study a novel 3D laser scanner in assessment of concrete's morphology subjected to grinding is presented. Moreover in order to understand better two bodies abrasive process the raw morphologic state is compared the ground concrete surfaces. The most significant results are presented in the form of three-dimensional images of axonometric projections and several surface determinable morphology parameters.

\section{Metrological strategy}

In order to take into consideration real civil engineering problem a few square meters has to be analyzed and for statistical reasons a significant number of measurements has to be carried out on pertinent areas of analyzed concrete. For that reasons 40 of $50 \times 50 \mathrm{~mm}$ concrete surfaces selected on a $125 \mathrm{~mm}$ thick concrete substrate layer were investigated. Also for technological reasons the concrete substrates were prepared of grade C30/37 concrete with the maximum grading of $8 \mathrm{~mm}$ of crushed basalt aggregate. The scanning field corresponds to the one tested by the semi-nondestructive pull-off method in order to identify the adhesion between concrete layers [16-18].

In order to discriminate the effect of grinding on large scale of machined concrete the surfaces were prepared differently:

- raw surface (half space as after concreting),

- ground (half space subjected to grinding).

A 3D laser scanner, developed and described in details in [11-14] was used. That 3D laser scanner principle (Fig. 1c) is based on triangulation modified method, exploiting a set of laser spots forming a $50 \mathrm{~mm}$ long line. In order to obtain a 3D image of the tested surface the scanner was equipped with a stepwise motor whereby measurements could be performed at a sampling range of $0.1 \mathrm{~mm}$ along a measuring length of $50 \mathrm{~mm}$. As mentioned in [15] in the case of highly rough surfaces, to which concrete surfaces belong, the laser triangulation method has a certain limitation (shadow effect) due to its principle of operation. However, in the case of measured ground concrete surfaces no influence of the shadow effect on the obtained results was observed taking several metrological precautions.

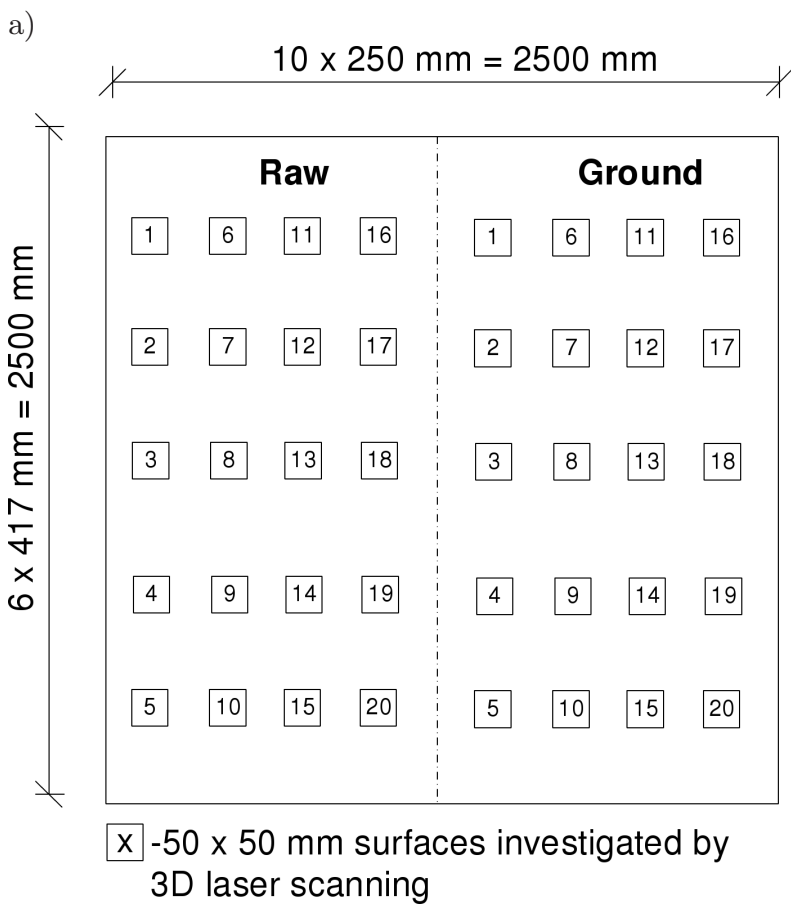

b)

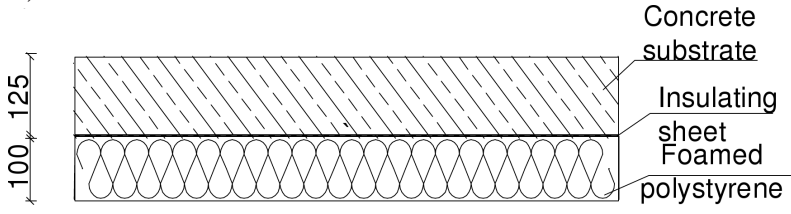

c)

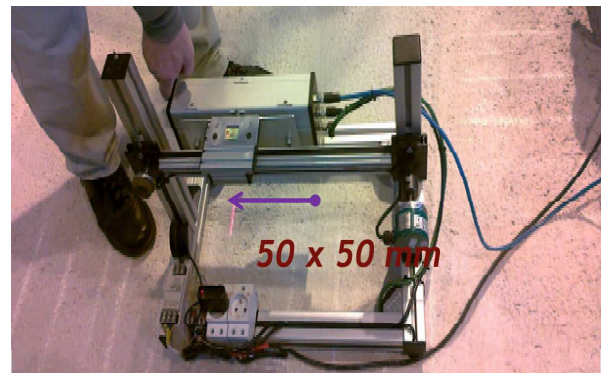

Fig. 1. View of selected surfaces locations (a) orthogonal section (b) 3D operating laser scanning device (c).

The main advantages of developed 3D laser scanner technique are its speed, achieved owing to the fitting of the scanning parameters to the measurement requirements, and its mobility.

\section{Selected results and discussion}

In order to illustrate the morphology evolution due to grinding process pertinent 3D isometric views, extracted significant profiles, and isotropy of the raw and ground concrete substrate surfaces are shown in Figs. 2 and 3. 
a)

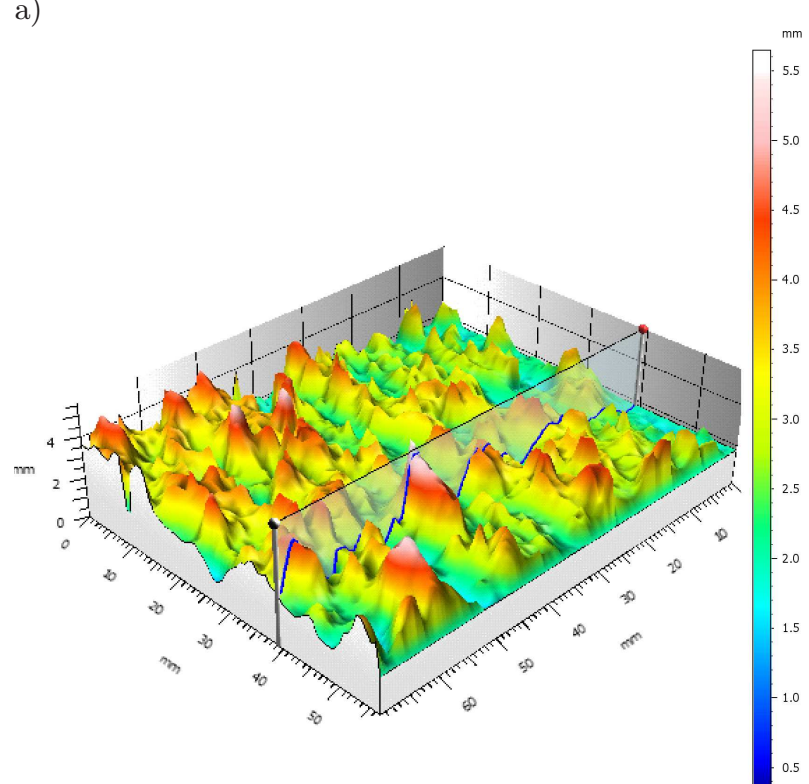

b)

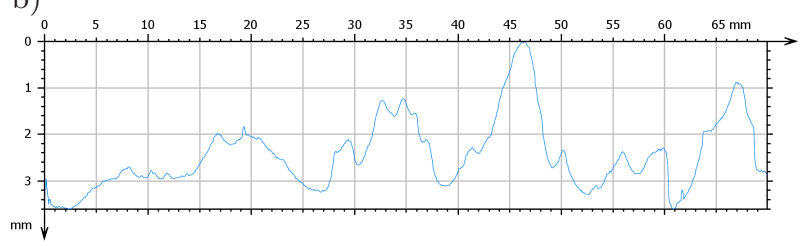

c)

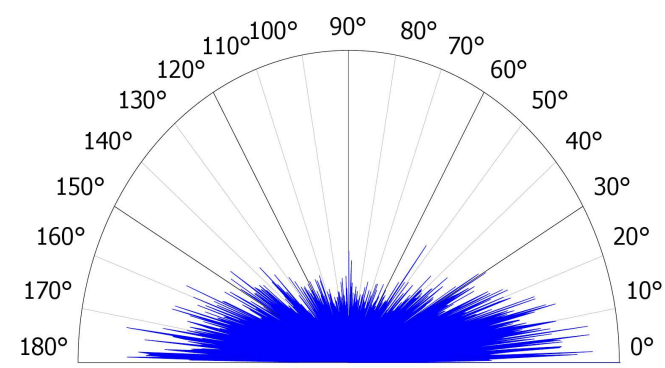

\begin{tabular}{|l|r|l|l|}
\hline Parameters & Value & Unit & \\
\hline Isotropy & 27.2 & $\%$ & \\
\hline First Direction & 0.300 & $\circ$ & \\
\hline
\end{tabular}

Fig. 2. 3D isometric view (a) profile (b) and isotropy analysis (c) of raw concrete surface.

From the analysis of Figs. 2 and 3 it is easy to state that profile of ground concrete surface is characterized by lower amplitude than for raw surface. It is the effect of cutting "peaks". From profile of Fig. 3 the crushing effect of emerging gravels can be easily observed. Interest to morphological anisotropy concrete is justified by directional flattening before solidification and it is attention-grabbing to measure if it is possible to quantify the effect of machining in case of present study grinding. Effectively the isotropy of ground concrete surface is twice higher than for the raw one. One can state that grinding process in present situation contributes to homogenization of ground surfaces.

a)
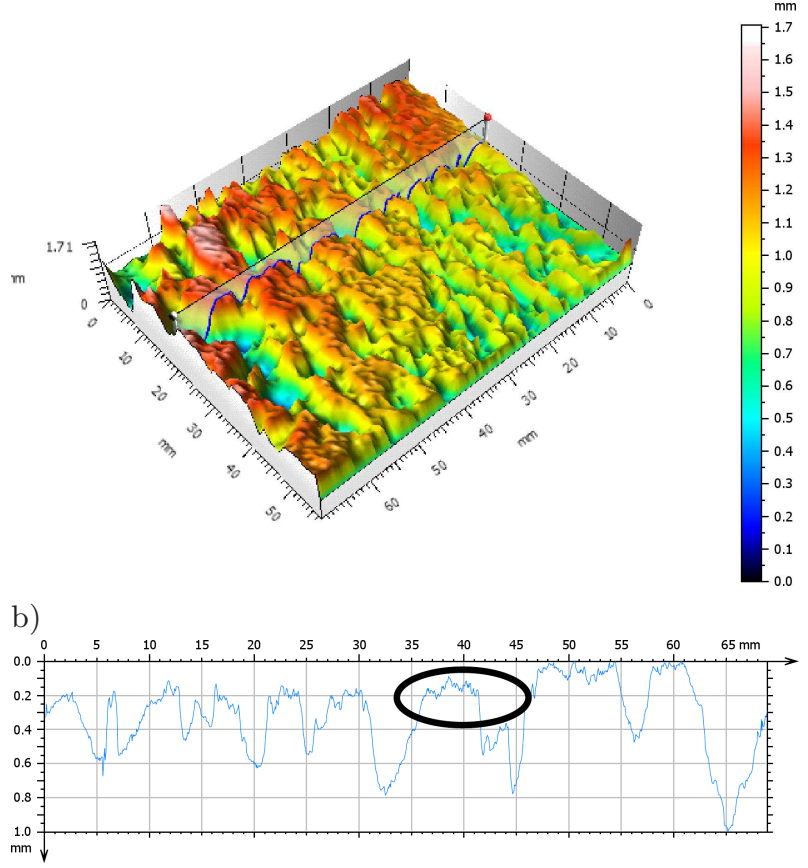

c)

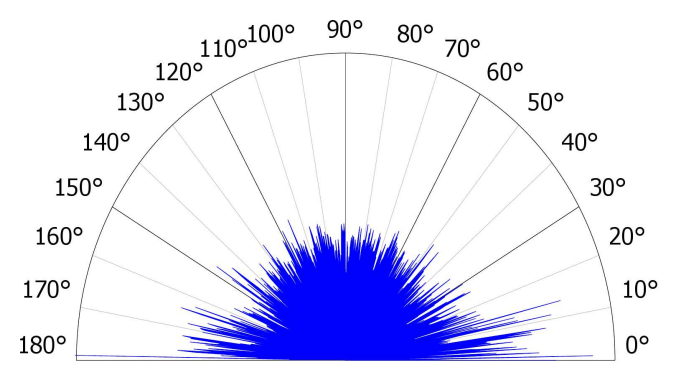

\begin{tabular}{|l|r|l|l|}
\hline Parameters & Value & Unit \\
\hline Isotropy & 39.6 & $\%$ & \\
\hline First Direction & 179 & $\circ$ & \\
\hline
\end{tabular}

Fig. 3. 3D isometric view (a) profile (b) and isotropy analysis (c) of ground concrete surface.

The morphological characterization and the surface roughness parameters were calculated thanks to MountainsMap [19] in accordance to ISO 25178 standards [20]. Statistical treatments of 3D morphological parameters (3D optical scanning) are presented in Tables $1-5$.

An analysis of the test results presented in Table 1 shows that the grinding of the concrete surface resulted in a reduction in the average values of all amplitude roughness parameters except $S k u$ in comparison with the average values of the same parameters describing the raw surface. 
Management and Production Engineering Review

Table 1

Statistical treatment of 3D morphological height parameters (3D optical scanning of concrete surfaces)

\begin{tabular}{c|c|c|c|c}
\hline \multirow{2}{*}{$\begin{array}{c}\text { Paramete } \\
\text { symbol }\end{array}$} & \multicolumn{5}{|c}{ Name and value of characteristic } \\
\cline { 2 - 5 } & \multicolumn{4}{|c}{ Raw concrete surface } \\
\cline { 2 - 5 } & Average & Min. & Max. & STD \\
\hline$S q[\mathrm{~mm}]$ & 0.718 & 0.398 & 1.140 & 0.200 \\
\hline$S s k[-]$ & 0.651 & -0.501 & 4.020 & 0.925 \\
\hline$S k u[-]$ & 4.923 & 2.560 & 5.200 & 1.884 \\
\hline$S p[\mathrm{~mm}]$ & 3.654 & 1.950 & 5.840 & 1.209 \\
\hline$S v[\mathrm{~mm}]$ & 2.150 & 0.779 & 3.450 & 0.748 \\
\hline$S z[\mathrm{~mm}]$ & 5.805 & 3.570 & 8.960 & 1.483 \\
\hline$S a[\mathrm{~mm}]$ & 0.559 & 0.306 & 0.928 & 0.173 \\
\hline & Ground concrete surface \\
\hline$S q[\mathrm{~mm}]$ & 0.253 & 0.137 & 0.484 & 0.085 \\
\hline$S s k[-]$ & -0.786 & -1.610 & 0.148 & 0.544 \\
\hline$S k u[-]$ & 4.240 & 1.990 & 6.650 & 1.495 \\
\hline$S p[\mathrm{~mm}]$ & 0.665 & 0.384 & 1.060 & 0.180 \\
\hline$S v[\mathrm{~mm}]$ & 1.269 & 0.658 & 2.320 & 0.456 \\
\hline$S z[\mathrm{~mm}]$ & 1.935 & 1.070 & 3.000 & 0.544 \\
\hline$S a[\mathrm{~mm}]$ & 0.198 & 0.105 & 0.416 & 0.071 \\
\hline
\end{tabular}

It appears from the Table 2 that grinding caused the largest reduction in the average values of parameters $S m c$ and $S x p$, but it had no effect on the value of parameter $S m r$, which did not change in comparison with that obtained for the surface not subjected to grinding process.

Table 2

Statistical treatment of 3D morphological selected functional parameters (3D optical scanning of concrete surfaces).

\begin{tabular}{c|c|c|c|c}
\hline \multirow{2}{*}{$\begin{array}{c}\text { Parameter } \\
\text { symbol }\end{array}$} & \multicolumn{5}{|c}{ Name and value of characteristic } \\
\cline { 2 - 5 } & \multicolumn{4}{|c}{ Raw concrete surface } \\
\cline { 2 - 5 } & Average & Min. & Max. & STD \\
\hline$S m r[\%]$ & 0.003 & 0.002 & 0.006 & 0.001 \\
\hline$S m c[\mathrm{~mm}]$ & 0.927 & 0.527 & 1.490 & 0.274 \\
\hline$S x p[\mathrm{~mm}]$ & 1.154 & 0.311 & 2.180 & 0.497 \\
\hline \multicolumn{5}{|c}{ Ground concrete surface } \\
\hline$S m r[\%]$ & 0.002 & 0.001 & 0.006 & 0.002 \\
\hline$S m c[\mathrm{~mm}]$ & 0.277 & 0.000 & 0.636 & 0.123 \\
\hline$S x p[\mathrm{~mm}]$ & 0.608 & 0.338 & 1.110 & 0.221 \\
\hline
\end{tabular}

An analysis of the statistical treatment of $3 \mathrm{D}$ morphological spatial parameters presented in Table 3 shows that the grinding of the concrete surface resulted in a reduction in the average values of two spatial roughness parameters Str in comparison with the average values of the same parameters describing the raw surface. Average value of $S a l$ increases in comparison with the ones described raw surface. However it is proper to note that the following changes are not more than $20 \%$ and changes of the average value of Std is not significant.
Table 3

Statistical treatment of 3D morphological spatial parameters (3D optical scanning of concrete surfaces).

\begin{tabular}{c|c|c|c|c}
\hline \multirow{2}{*}{$\begin{array}{c}\text { Parameter } \\
\text { symbol }\end{array}$} & \multicolumn{5}{|c}{ Name and value of characteristic } \\
\cline { 2 - 5 } & \multicolumn{4}{|c}{ Raw concrete surface } \\
\cline { 2 - 5 } & Average & Min. & Max. & STD \\
\hline Sal $[\mathrm{mm}]$ & 3.694 & 2.230 & 9.670 & 1.549 \\
\hline Str $[-]$ & 0.555 & 0.225 & 0.835 & 0.191 \\
\hline Std $\left[^{\circ}\right]$ & 66.119 & 3.000 & 177.000 & 82.200 \\
\hline \multicolumn{5}{|c}{ Ground concrete surface } \\
\hline Sal $[\mathrm{mm}]$ & 3.971 & 1.700 & 9.790 & 2.483 \\
\hline Str $[-]$ & 0.472 & 0.132 & 0.687 & 0.164 \\
\hline Std $\left[^{\circ}\right]$ & 64.845 & 0.335 & 176.000 & 71.370 \\
\hline
\end{tabular}

It can be stated from the Table 4 that grinding caused the largest reduction in the average values of both hybrid parameters Sdq and Sdr in comparison with that obtained for the surface not subjected to grinding.

Table 4

Statistical treatment of 3D morphological hybrid parameters (3D optical scanning of concrete surfaces).

\begin{tabular}{|c|c|c|c|c|}
\hline \multirow{3}{*}{$\begin{array}{c}\text { Parameter } \\
\text { symbol }\end{array}$} & \multicolumn{4}{|c|}{ Name and value of characteristic } \\
\hline & \multicolumn{4}{|c|}{ Raw concrete surface } \\
\hline & Average & Min. & Max. & STD \\
\hline$S d q[-]$ & 2.653 & 0.918 & 4.670 & 1.035 \\
\hline$S d r[\%]$ & 156.165 & 22.600 & 391.000 & 99.865 \\
\hline \multicolumn{5}{|c|}{ Ground concrete surface } \\
\hline$S d q[-]$ & 0.488 & 0.330 & 0.713 & 0.097 \\
\hline$S d r[\%]$ & 10.362 & 5.030 & 17.600 & 3.336 \\
\hline
\end{tabular}

By analysis the results from Table 5 it also can be stated that grinding caused the largest reduction in the average values of all volume parameters in comparison with that obtained for the surface not subjected to grinding process.

Table 5

Statistical treatment of 3D morphological volume parameters (3D optical scanning of concrete surfaces).

\begin{tabular}{|c|c|c|c|c|}
\hline \multirow{3}{*}{$\begin{array}{c}\text { Parameter } \\
\text { symbol }\end{array}$} & \multicolumn{4}{|c|}{ Name and value of characteristic } \\
\hline & \multicolumn{4}{|c|}{ Raw concrete surface } \\
\hline & Average & Min. & Max. & STD \\
\hline$V m\left[\mathrm{~mm}^{3} / \mathrm{mm}^{2}\right]$ & 0.045 & 0.026 & 0.088 & 0.015 \\
\hline$V v\left[\mathrm{~mm}^{3} / \mathrm{mm}^{2}\right]$ & 0.973 & 0.554 & 1.560 & 0.279 \\
\hline$V m p\left[\mathrm{~mm}^{3} / \mathrm{mm}^{2}\right]$ & 0.045 & 0.026 & 0.088 & 0.015 \\
\hline$V m c\left[\mathrm{~mm}^{3} / \mathrm{mm}^{2}\right]$ & 0.598 & 0.277 & 1.070 & 0.216 \\
\hline$V v c\left[\mathrm{~mm}^{3} / \mathrm{mm}^{2}\right]$ & 0.910 & 0.516 & 1.490 & 0.266 \\
\hline$V v v\left[\mathrm{~mm}^{3} / \mathrm{mm}^{2}\right]$ & 0.063 & 0.014 & 0.141 & 0.030 \\
\hline \multicolumn{5}{|c|}{ Ground concrete surface } \\
\hline$V m\left[\mathrm{~mm}^{3} / \mathrm{mm}^{2}\right]$ & 0.008 & 0.003 & 0.024 & 0.005 \\
\hline$V v\left[\mathrm{~mm}^{3} / \mathrm{mm}^{2}\right]$ & 0.294 & 0.137 & 0.650 & 0.111 \\
\hline$V m p\left[\mathrm{~mm}^{3} / \mathrm{mm}^{2}\right]$ & 0.008 & 0.003 & 0.024 & 0.005 \\
\hline$V m c\left[\mathrm{~mm}^{3} / \mathrm{mm}^{2}\right]$ & 0.225 & 0.116 & 0.503 & 0.086 \\
\hline$V v c\left[\mathrm{~mm}^{3} / \mathrm{mm}^{2}\right]$ & 0.256 & 0.108 & 0.611 & 0.106 \\
\hline$V v v\left[\mathrm{~mm}^{3} / \mathrm{mm}^{2}\right]$ & 0.037 & 0.022 & 0.070 & 0.014 \\
\hline
\end{tabular}




\section{Conclusion and perspectives}

It has been demonstrated that metrology of ground concrete's morphology is possible and necessary in manufacturing of this surfaces of high value added processes. The non-destructive metrology of the morphology of ground concrete in relation to raw surface can be determinist and is discriminative by means of 3D laser scanner measurements.

It appears from the selected results that grinding process contributes to reduction in the average values of most 3D topographical parameters. Only average values of spatial parameters have been stated as similar.

It is still the open problem to select the most relevant 3D morphological descriptors as pertinent parameters for specific function of raw as well as finished surfaces by grounding of concrete.

In developing the ideas presented here authors have received helpful from Dr. Jacek Reiner from Wroclaw University of Technology for constructing $3 D$ laser scanner and Dr. Sebastian Stach from University of Silesia in Katowice for preparing the data for the analysis. Authors would like to thank also Mr. François Blateyron from Digital Surf for assistance in Mountains soft make use of.

\section{References}

[1] Mathia T., Pawlus P., Wieczorowski M., Recent trends in surface metrology, Wear, 271, 494-508, 2011.

[2] Garbacz A., Courard L., Bissonnette B., A surface engineering approach applicable to concrete repair engineering, Bulletin of the Polish Academy of Sciences: Technical Sciences, 61, 1, 73-84, 2013.

[3] Santos P., Julio E., A state-of-the-art review on roughness quantification methods for concrete surfaces, Construction and Building Materials, 38, 912923, 2013.

[4] Gawlik J., Kiełbus A., Karpisz D., New approach to integrated data management in special materials processing, Advances in Manufacturing Science and Technology, 38, 1, 23-35, 2014.

[5] Fisco N., Sezen H., Comparison of surface macrotexture measurement methods, Journal of Civil Engineering and Management, 19, 1 (Supplement), S153-S160, 2013.

[6] Feldshtein E., Dyachkova L., Surface texture of sintered iron-graphite MMCs infiltrated by copper alloys after grinding, Advances in Manufacturing Science and Technology, 37, 4, 69-76, 2013.

[7] Santos P., Júlio E., Comparison of methods for texture assessment of concrete surfaces, ACI Materials Journal, 107, 5, 433-440, 2010.
[8] Niemczewska-Wójcik M., Mathia T., Wójcik A., Measurement Techniques Used for Analysis of the Geometric Structure of Machined Surfaces, Management and Production Engineering Review, 5, 2, 2732, 2014.

[9] Whitehouse D., The parameter rash-is there a cure?, Wear, 83, 75-78, 1982.

[10] Pawlus P., Wieczorowski M., Mathia T., The Errors of Stylus Methods in Surface Topography Measurements, Editor Zapol, ISBN 98-78-83-7518-699-4, 2014.

[11] Sadowski L., Nondestructive assessment of the bond between concrete layers in floors by means of artificial neural networks [in Polish], PhD thesis, Wrocław University of Technology, Wroclaw, 2012.

[12] Czarnecki S., Hoła J., Sadowski L., A nondestructive method of investigating the morphology of concrete surfaces by means of newly designed $3 D$ scanner, 11th European Conference on Nondestructive Testing, 6-10 October 2014, Prague, Czech Republic.

[13] Hoła J., Sadowski Ł., Reiner J., Stach S., Usefulness of $3 D$ surface roughness parameters for nondestructive evaluation of pull-off adhesion of concrete layers, Construction and Building Materials, 84, 111120,2015 .

[14] Sadowski L., Application of three-dimensional optical laser triangulation method for concrete surface morphology measurement, Indian Journal of Engineering \& Materials Sciences, 21, 692-700, 2014.

[15] Czarnecki S., Hoła J., Sadowski Ł., The Use of a 3D Scanner for Evaluating the Morphology of a Sandblasted Concrete Surface, Key Engineering Materials, 2015 (accepted).

[16] Sadowski L., Non-destructive evaluation of the pulloff adhesion of concrete floor layers using RBF neural Network, Journal of Civil Engineering and Management, 19, 4, 550-560, 2013.

[17] Sadowski L., Hoła J., Neural prediction of the pulloff adhesion of the concrete layers in floors on the basis of nondestructive tests, Procedia Engineering, 57, 986-995, 2013.

[18] Sadowski L., Hoła J., New nondestructive way of identifying the values of pull-off adhesion between concrete layers in floors, Journal of Civil Engineering and Management, 20, 4, 561-569, 2014.

[19] http://www.digitalsurf.com (access 06.2014).

[20] ISO 25178-2. Geometrical product specifications (GPS) - Surface texture: Areal - Part 2: Terms, definitions and surface texture parameters, 2012. 